\title{
Cosorption of Sulfur Dioxide and Water on Cork
}

\author{
Sonia Lequin,,$^{1,2,3}$ David Chassagne, ${ }^{1,2}$ Thomas Karbowiak, ${ }^{2}$ \\ and Jean-Pierre Bellat ${ }^{3 *}$
}

\begin{abstract}
The cosorption of gaseous sulfur dioxide $\left(\mathrm{SO}_{2}\right)$ and water vapor $\left(\mathrm{H}_{2} \mathrm{O}\right)$ on raw cork powder by using calorimetry coupled with manometry at $298 \mathrm{~K}$ was studied. Sorption isotherms of single components confirm the previous results obtained by thermogravimetry: $\mathrm{SO}_{2}$ is well chemisorbed on cork surface while $\mathrm{H}_{2} \mathrm{O}$ is only physisorbed. Moreover, the interaction of $\mathrm{SO}_{2}$ and $\mathrm{H}_{2} \mathrm{O}$ with cork appears more like an absorption process than an adsorption process. Competitive sorption of $\mathrm{SO}_{2}$ and $\mathrm{H}_{2} \mathrm{O}$ first occurs in favor of $\mathrm{SO}_{2}$ chemisorption. After all chemisorption sites are saturated by $\mathrm{SO}_{2}$, the cosorption process becomes selective for $\mathrm{H}_{2} \mathrm{O}$. The amount of $\mathrm{SO}_{2}$ sorbed on cork is rather low compared to $\mathrm{H}_{2} \mathrm{O}$. Results indicate that the sorption of $\mathrm{SO}_{2}$ on cork cannot explain the decrease in $\mathrm{SO}_{2}$ content observed during wine aging in bottle.
\end{abstract}

Key words: cosorption, sulfur dioxide, water, cork, calorimetry, selectivity

Wine production has long been affected by premature oxidation reactions occurring in wine stored in bottle (RibéreauGayon 1963, Singleton 1987, Wildenradt and Singleton 1974). The main molecules responsible for oxidation are oxygen $\left(\mathrm{O}_{2}\right)$ and its derived species, which react with wine polyphenols (Rossi and Singleton 1966, Waterhouse and Laurie 2006). Oxidation can eventually lead to sensory defaults (off flavors, browning), resulting in rejection by consumers (Escudero et al. 2002). Oxygen is essentially brought to wine during winemaking and also during storage by oxygen transfer through the bottle stopper (Karbowiak et al. 2010, Valade et al. 2007, Vidal et al. 2004). The choice of the sealing material is therefore important.

Natural cork stopper has been the most common material used for bottling, given its low permeability to liquids and gases. Cork is constituted by alveolar cells arranged without intercellular spaces (Gibson et al. 1981). These cells are mainly composed of suberin $(\sim 50 \% \mathrm{~m} / \mathrm{m})$, a rather hydrophobic compound with long aliphatic chains of fatty acid and some aromatic domains. The other major compounds present in cork are lignin $(\sim 30 \% \mathrm{~m} / \mathrm{m})$ and cellulose $(\sim 20 \% \mathrm{~m} / \mathrm{m})$ (Pereira 2007, Silva et al. 2005). Such structure and chemical composition provide cork with good barrier properties. How-

${ }^{1}$ Institut Universitaire de la Vigne et du Vin, 1 rue Claude Ladrey, ${ }^{2}$ EMMA EA 581, Agrosup Dijon, 1 esplanade Erasme, and ${ }^{3}$ Laboratoire Interdisciplinaire Carnot de Bourgogne, ICB UMR 5209 CNRS, 9 avenue Alain Savary, Université de Bourgogne, F-21078 Dijon, France.

*Corresponding author (email: jean-pierre.bellat@u-bourgogne.fr; fax: +33 (0) 380396132 )

Acknowledgments: The authors gratefully acknowledge the Bureau Interprofessionnel des Vins de Bourgogne and the Regional Council of Burgundy for financial support of this work.

The authors thank Christian Paulin, ICB (Dijon), for assistance on calorimetry experiments.

Manuscript submitted Jan 2011, revised Sept 2011, accepted Oct 2011. Publication costs of this article defrayed in part by page fees.

Copyright $(\subset) 2012$ by the American Society for Enology and Viticulture. All rights reserved.

doi: $10.5344 /$ ajev.2011.11058 ever, oxidation reactions can randomly occur in wine during bottle aging. In order to reduce this phenomenon, sulfur dioxide $\left(\mathrm{SO}_{2}\right)$ is generally added before bottling as an antioxidant. However, it has been shown that $\mathrm{SO}_{2}$ concentration can abnormally decrease after four months of storage (Brajkovich et al. 2005) and thus wine becomes less protected against oxidation. The question arises as to whether this decrease results from the sorption of $\mathrm{SO}_{2}$ on cork or from the diffusion of $\mathrm{SO}_{2}$ through cork. Moreover, in real conditions of wine storage, either in vertical or horizontal bottles, cork is highly hydrated. Thus, a second question arises concerning the possibility of hydration to favor the sorption and reactivity of cork with other molecules, such as $\mathrm{SO}_{2}$. Although cork has been used as stopper material for several centuries, interactions of $\mathrm{SO}_{2}$ and $\mathrm{H}_{2} \mathrm{O}$ with cork are not yet fully understood. To our knowledge, no data are reported on cork and $\mathrm{SO}_{2}$ interactions and only limited data on cork and water (Abdulla et al. 2009, Adrados and Haro 1994, Gil and Cortiço 1998). Thus, over the past few years, we have undertaken basic research on the interaction of these molecules on natural cork. Previous work used thermogravimetry and differential calorimetry to study the sorption of $\mathrm{SO}_{2}$ and $\mathrm{H}_{2} \mathrm{O}$ molecules individually in the gas state on crude cork, either dry or partially hydrated, and showed that $\mathrm{SO}_{2}$ is chemisorbed on cork while $\mathrm{H}_{2} \mathrm{O}$ is only physisorbed (Lequin et al. 2009, 2010). Surprisingly, we demonstracted that $\mathrm{SO}_{2}$ is sorbed to a lesser extent when $\mathrm{H}_{2} \mathrm{O}$ is previously sorbed on cork. To explain this decrease of the sorption capacity of $\mathrm{SO}_{2}$ in the presence of $\mathrm{H}_{2} \mathrm{O}$, we suggested a competitive sorption between water and $\mathrm{SO}_{2}$.

The aim of the present paper is to confirm that $\mathrm{SO}_{2}$ is selectively sorbed on cork in the presence of $\mathrm{H}_{2} \mathrm{O}$. To that purpose, we report here a complete thermodynamic study of the cosorption of $\mathrm{H}_{2} \mathrm{O}$ and $\mathrm{SO}_{2}$ in the gas phase on cork by using manometry coupled with calorimetry, which is more appropriate than thermogravimetry for studying cosorption. The sorption of single components was studied first, and then the sorption of a binary mixture was realized to investigate the competitive sorption between water and sulfur dioxide and to determine the sorption selectivity and cosorption enthalpy 
as a function of the sorbed amount. Results obtained here should help to elucidate the interaction mechanisms of some wine active compounds with cork and to confirm whether the sorption on this material is or is not responsible for the decrease in $\mathrm{SO}_{2}$ content observed during wine aging in bottle.

\section{Materials and Methods}

Materials. Raw cork stoppers, from Quercus suber L. in the Mora (Portugal) production area, were supplied by the Bouchons Trescases S.A. (Boulou, France). Stoppers were neither washed nor treated on surface (with paraffin or silicone) prior to use. Powder was made by grating cork stopper with a rasp. After sieving, the mean particle size was less than $500 \mu \mathrm{m}$. Nitrogen as well as krypton adsorptions at 77 $\mathrm{K}$ indicated that cork did not exhibit any specific surface area.

Experimental technique. The sorption of single components and binary mixture was studied by using a homemade manometric apparatus coupled with a heat-flow Setaram C80 differential calorimeter (Setaram, Caluire, France). This setup was connected to a HP 4890 gas-phase chromatograph (Agilent Technologies, Santa Clara, CA) equipped with a TCD detector and a Chrompack Bentone 34 packed column (Supelco, Saint-Germain-en-Laye, France). A bypass system connected to the vacuum line (turbomolecular pump) and composed of a six-way gas injection valve with sample loop allowed collection of a small amount of gas under low pressure for chromatographic analysis. This device has been described in detail in previous studies (Moise and Bellat 2005, Weber et al. 2008).

The sorption isotherms of single components were measured step-by-step by placing small successive doses of gas in contact with the sample. For each pressure step, measurement of the pressure before and after sorption allowed calculation of the amount sorbed. Two consecutive sorption isotherms were performed on the same sample (outgassing under vacuum was applied before the second sorption isotherm without changing the temperature) to determine whether chemisorption occurred on the material.

Cosorption isotherms were obtained by following the same procedure. However, in this case, in addition to measuring the pressure, the composition of the gas was also analyzed by gas chromatography before and after each sorption step. The initial molar fraction in the gas mixture was 0.67 for $\mathrm{SO}_{2}$ and 0.33 for $\mathrm{H}_{2} \mathrm{O}$. The sorbed amount $\left(n_{i}^{a}\right)$ and the molar fraction in the sorbate $\left(x_{i}\right)$ were calculated for each component $i$ by performing a mass balance in the gas phase from the total pressure $(p)$ and the molar fraction of component $i$ in the gas phase $\left(y_{i}\right)$, measured at equilibrium. Thus, it was possible to calculate the sorption selectivity of sulfur dioxide with respect to water, as defined by the following relation:

$$
\alpha_{\mathrm{SO}_{2} / \mathrm{H}_{2} \mathrm{O}}=\frac{x_{\mathrm{SO}_{2}} \cdot y_{\mathrm{H}_{2} \mathrm{O}}}{x_{\mathrm{H}_{2} \mathrm{O}} \cdot y_{\mathrm{SO}_{2}}}
$$

The mass of cork powder was $\sim 640 \mathrm{mg}$. Before each experiment, cork powder was outgassed in situ under vacuum $\left(10^{-5} \mathrm{hPa}\right)$ at $298 \mathrm{~K}$ for $72 \mathrm{hr}$. For all experiments, the pressure ranged from $0.1 \mathrm{hPa}$ to a maximum of $25 \mathrm{hPa}$ in order to avoid the condensation of water vapor.

\section{Results and Discussion}

Sorption of single components. Sorption isotherms of water (Figure 1) and sulfur dioxide (Figure 2) were determined and given in mmol per gram of dry cork activated under vacuum. Values are similar to those measured previously by thermogravimetry, which is a more accurate technique for studying sorption of gases on solids (Lequin et al. 2009, 2010). In both cases, the isotherms show a shape similar to the type II of the IUPAC classification (Sing et al. 1985). The same isotherm shape has been observed for sorption of water in hydrophilic polymers (Toribio et al. 2004). For $\mathrm{H}_{2} \mathrm{O}$,

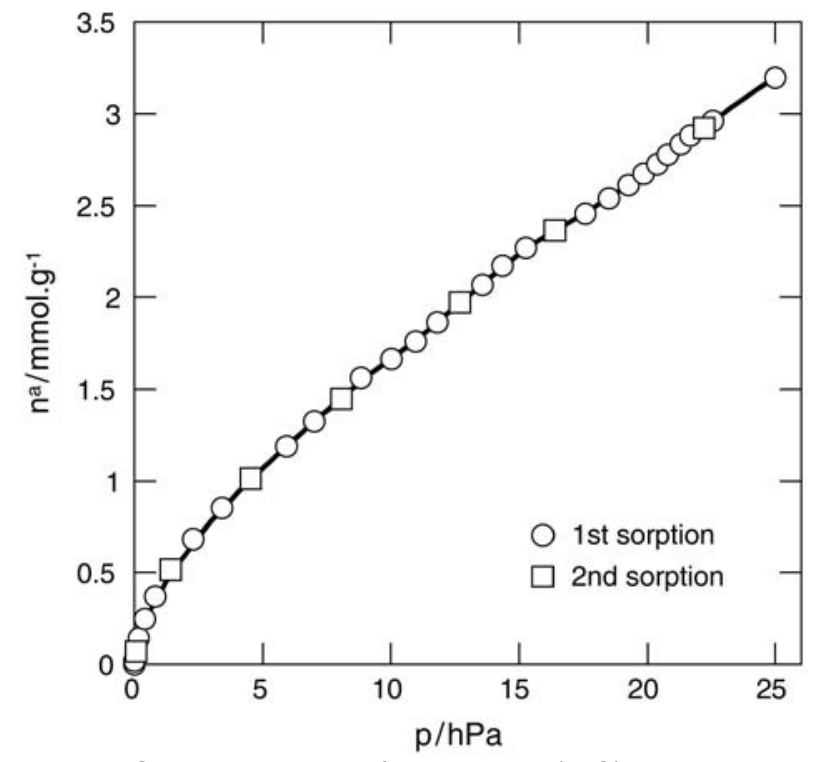

Figure 1 Sorption isotherm of water vapor $\left(\mathrm{H}_{2} \mathrm{O}\right)$ on dry cork powder at $298 \mathrm{~K}$.

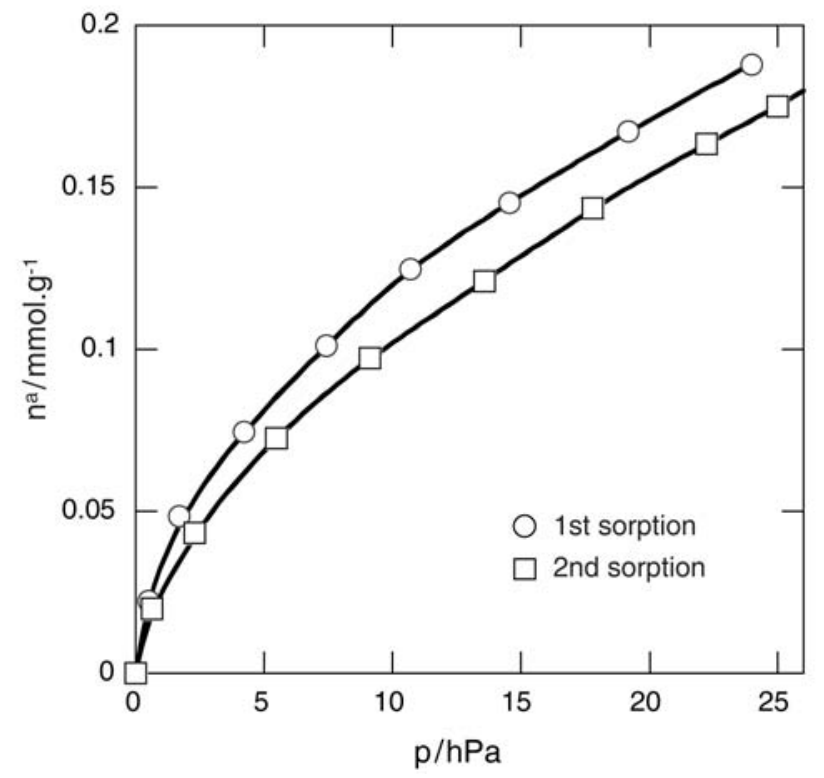

Figure 2 Sorption isotherm of sulfur dioxide $\left(\mathrm{SO}_{2}\right)$ on dry cork powder at $298 \mathrm{~K}$. 
first and second sorption isotherms were indistinguishable (Figure 1), indicating that no water remained sorbed after outgassing under vacuum. That was not the case with $\mathrm{SO}_{2}$ (Figure 2), in that the second sorption was lower than the first sorption. Moreover, $\mathrm{SO}_{2}$ was not completely removed by pumping under dynamic vacuum after the first sorption, indicating that $\mathrm{SO}_{2}$ was chemisorbed on the surface, as was previously determined by thermogravimetry (Lequin et al. 2009). The difference between first and second sorption allowed for calculating the chemisorbed quantity, which was $\sim 0.024$ mol.g- ${ }^{-1}$.

It is also important to note that previous experiments performed by thermogravimetry using $\mathrm{SO}_{2}$ or $\mathrm{H}_{2} \mathrm{O}$ did not show much difference in sorbed quantities between massive cork slices and cork powder (Lequin et al. 2009, 2010). Thus, studying sorption on powder gives valuable results. Cork powder was used in this work to obtain more precise accuracy in the thermal transfers measured by calorimetry.

The sorption capacities and the Henry constants of sorption are reported (Table 1). Under $25 \mathrm{hPa}$, the molar sorption capacity was 17 times higher for $\mathrm{H}_{2} \mathrm{O}$ than for $\mathrm{SO}_{2}$. The number of sorption sites is thus very different for these two molecules. $\mathrm{SO}_{2}$ molecules are likely chemisorbed on specific sites, which do not interact with $\mathrm{H}_{2} \mathrm{O}$. Henry constants are calculated from the slope of the sorption isotherms when the pressure tends to zero and from the saturated vapor pressure $\left(p_{s}\right)$ of the gas at $298 \mathrm{~K}$ according to the relation:

$$
n_{p \rightarrow 0}^{a}=K_{H} \frac{p}{p_{s}}
$$

Such a calculation allows for comparison of the Henry constants of the two gases. Results show that $\mathrm{K}_{\mathrm{H}}$ was approximately eight times higher for $\mathrm{SO}_{2}$ than for $\mathrm{H}_{2} \mathrm{O}$, revealing a stronger sorption affinity of cork for $\mathrm{SO}_{2}$ than for $\mathrm{H}_{2} \mathrm{O}$. Therefore, for sorption of the binary mixture $\mathrm{SO}_{2}+\mathrm{H}_{2} \mathrm{O}$, we can expect that the sorption will be in favor of $\mathrm{SO}_{2}$ at low pressure. However, as the sorption capacity of $\mathrm{H}_{2} \mathrm{O}$ largely exceeds that of $\mathrm{SO}_{2}$, it is possible that the sorption process becomes selective for $\mathrm{H}_{2} \mathrm{O}$ when the pressure increases.

Calorimetric sorption enthalpies of water and sulfur dioxide individually on cork powder are given as absolute values (Table 1). These sorption enthalpies are also represented versus loading (Figure 3). For water, only values at very low loading are represented. The sorption enthalpy of water at zero loading was $\sim 60 \mathrm{~kJ}^{\mathrm{mol}}{ }^{-1}$, typical of a physisorption process. A detailed study of this sorption mechanism has been demonstrated previously (Lequin et al. 2010). For sulfur dioxide,

Table 1 Henry constants, sorption capacities, and sorption enthalpies of $\mathrm{SO}_{2}$ and $\mathrm{H}_{2} \mathrm{O}$ on dry cork at $298 \mathrm{~K}$.

\begin{tabular}{lcc}
\hline & $\mathrm{SO}_{2}$ & $\mathbf{H}_{2} \mathbf{O}$ \\
\hline $\mathrm{K}_{\mathrm{H}}\left(\mathrm{mmol}^{-1}\right)$ & 160 & 19 \\
$n_{\max }^{a}$ at $25 \mathrm{hPa}\left(\mathrm{mmol} . \mathrm{g}^{-1}\right)$ & 0.19 & 3.2 \\
$\mid \Delta H_{n^{a} \rightarrow 0}^{a}\left(\mathrm{~kJ} . \mathrm{mol}^{-1}\right)$ & $>90\left(1^{\text {st }}\right.$ sorption $)$ & $\sim 60$ \\
\hline
\end{tabular}

the sorption enthalpy at zero loading was $90 \mathrm{~kJ}^{\mathrm{mol}}{ }^{-1}$ for the first sorption and did not exceed $50 \mathrm{~kJ} \cdot \mathrm{mol}^{-1}$ for the second sorption, confirming that $\mathrm{SO}_{2}$ was chemisorbed on the surface. Then, as loading increased, the sorption enthalpy decreased to the liquefaction enthalpy. No important sorbate-sorbate $\left(\mathrm{SO}_{2}-\right.$ $\mathrm{SO}_{2}$ ) interactions were observed at high loading. The $\mathrm{SO}_{2}$ molecules sorbed on cork were likely too far apart to interact. According to calorimetric results, sorbate-sorbent interactions were stronger for $\mathrm{SO}_{2}$ than for $\mathrm{H}_{2} \mathrm{O}$ at low loading, whereas sorbate-sorbate interactions become predominant for $\mathrm{H}_{2} \mathrm{O}$ at high loading (Lequin et al. 2010), reinforcing the conclusion deduced from the Henry constants. In the case of the cosorption of $\mathrm{SO}_{2}$ and $\mathrm{H}_{2} \mathrm{O}$, we can expect to have a sorption process selective for $\mathrm{SO}_{2}$ at low loading and for $\mathrm{H}_{2} \mathrm{O}$ at high loading.

Sorption of binary mixture. Total and partial sorption isotherms of sulfur dioxide and water are shown (Figure 4). The major component in the sorbed phase was $\mathrm{SO}_{2}$. The composition of the sorbed phase was not very different than the composition of the initial gas mixture. However, that does not indicate that the sorption process is obviously in favor of $\mathrm{SO}_{2}$. As the initial mixture is very rich in this compound, it is not abnormal to retrieve it in majority in the sorbed phase. Only the sorption selectivity, which takes into account the molar fractions of each component in the sorbed and gas phases, can give information on the preferential sorption of $\mathrm{SO}_{2}$ or $\mathrm{H}_{2} \mathrm{O}$.

The dependence of the total loading on the sorption selectivity of $\mathrm{SO}_{2}$ with respect to $\mathrm{H}_{2} \mathrm{O}\left(\mathrm{\alpha}_{\mathrm{SO}_{2} / \mathrm{H}_{2} \mathrm{O}}\right)$ is shown (Figure 5), and the curve exhibits three distinct regions, or steps. At the beginning of the sorption, $\alpha$ is $>1$ and increases with loading to reach a maximal value of 2.4 at a total loading of $0.033 \mathrm{mmol} . \mathrm{g}^{-1}$. The partial amount of $\mathrm{SO}_{2}$ sorbed at this total loading is equal to $0.028 \mathrm{mmol} . \mathrm{g}^{-1}$, which is very close to the amount of the single $\mathrm{SO}_{2}$ chemisorbed on cork. Moreover, the

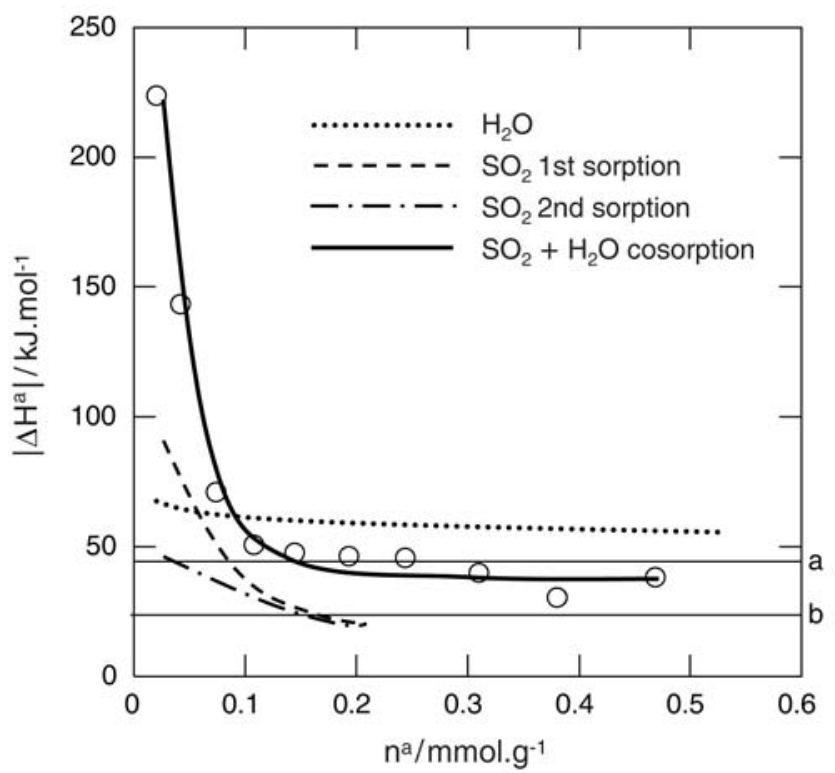

Figure 3 Cosorption enthalpy (absolute value) of $\mathrm{H}_{2} \mathrm{O}$ and $\mathrm{SO}_{2}$ on cork powder at $298 \mathrm{~K}$ versus loading (open symbols). Initial composition of the mixture: $0.67 \mathrm{SO}_{2}+0.33 \mathrm{H}_{2} \mathrm{O}$. Sorption enthalpy of single components are also reported (a: liquefaction enthalpy of water $=44 \mathrm{~kJ} \cdot \mathrm{mol}^{-1}$; b: liquefaction enthalpy of $\left.\mathrm{SO}_{2}=22.9 \mathrm{~kJ} \cdot \mathrm{mol}^{-1}\right)$. 
cosorption enthalpy is very high in this region, with values

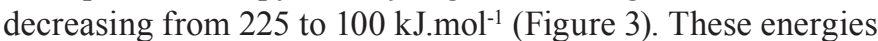
are typical of chemical bonds. Therefore, this first cosorption step can be unambiguously attributed to the selective chemisorption of $\mathrm{SO}_{2}$. For loading between 0.033 and $0.15 \mathrm{mmol}^{-1}{ }^{-1}$, the sorption selectivity sharply decreases; above $0.1 \mathrm{mmol} . \mathrm{g}^{-1}$, the selectivity becomes less than 1 . The cosorption heat continues to decrease to the liquefaction enthalpy of water (44 $\mathrm{kJ} . \mathrm{mol}^{-1}$ ). In this second cosorption step, all chemisorption sites for $\mathrm{SO}_{2}$ are saturated and the cosorption process, which is now only a physisorption of $\mathrm{SO}_{2}$ and $\mathrm{H}_{2} \mathrm{O}$, turns in favor

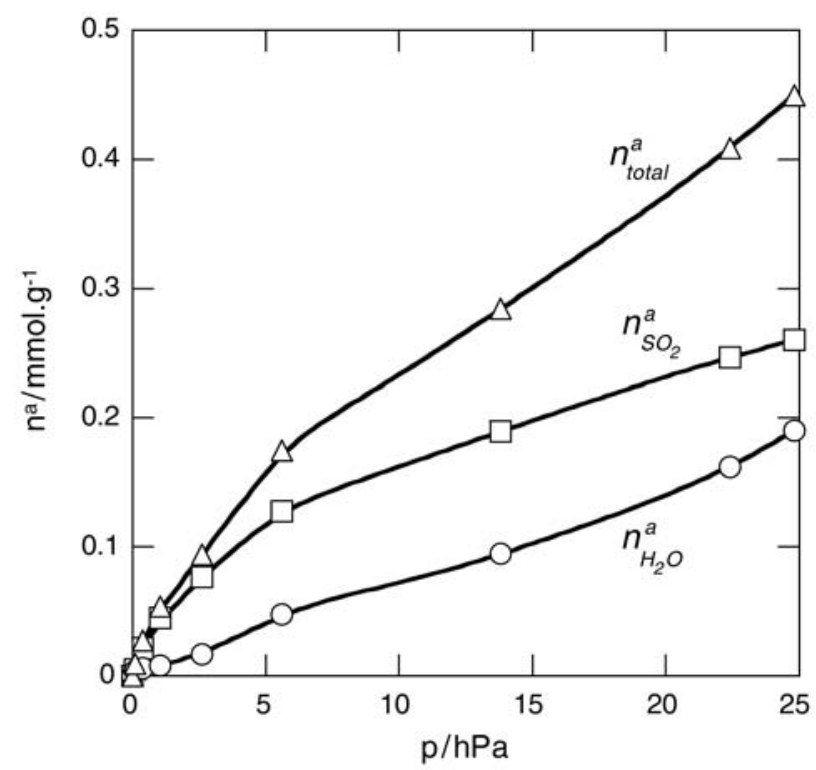

Figure 4 Total and partial sorption isotherms of water and sulfur dioxide for the binary mixture composed of 0.33 molar water and 0.67 molar sulfur dioxide.

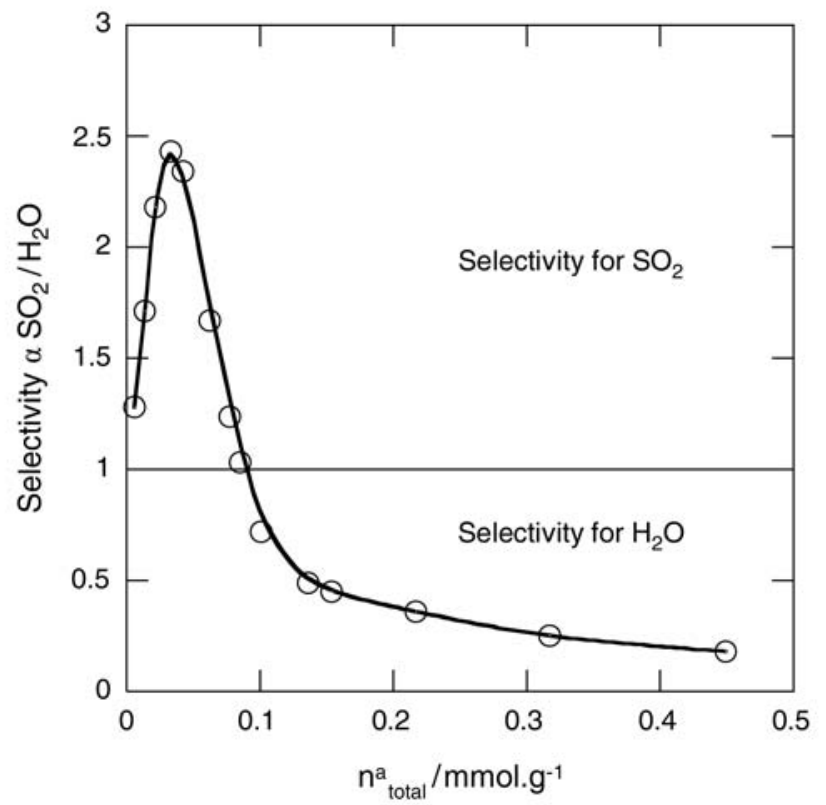

Figure 5 Dependence of the total loading on the sorption selectivity of $\mathrm{SO}_{2}$ with respect to $\mathrm{H}_{2} \mathrm{O}$ at $298 \mathrm{~K}$. Initial molar composition of the mixture: $0.67 \mathrm{SO}_{2}+0.33 \mathrm{H}_{2} \mathrm{O}$. of the sorption of $\mathrm{H}_{2} \mathrm{O}$. Above $0.15 \mathrm{mmol} . \mathrm{g}^{-1}$, the sorption selectivity still decreases with loading, but to a lesser extent (Figure 5). The selectivity tends to $\sim 0.15$ at high loading. In this range, the cosorption heat remains constant and equal to the liquefaction enthalpy of water (Figure 3), suggesting that in this third cosorption step only water molecules are sorbed on cork. There is a significant change in the slopes of total and partial sorption isotherms above this total loading of 0.15 mmol.g ${ }^{-1}$ (Figure 4).

In a recent work devoted to the sorption of $\mathrm{SO}_{2}$ on partially hydrated cork studied by calorimetry (Lequin et al. 2009), we obtained, for the sorption enthalpy of $\mathrm{SO}_{2}$ as a function of the loading, a bell curve shape, as for the selectivity shown in Figure 5. At that time, we suspected that the increase of the sorption enthalpy of $\mathrm{SO}_{2}$ at low loading was due to the chemisorption of $\mathrm{SO}_{2}$ on cork. The results obtained here unambiguously confirm this assumption.

\section{Conclusion}

This work reports a thermodynamic study of cosorption of water and sulfur dioxide on raw cork at $298 \mathrm{~K}$ by using an original technique that combines manometry and calorimetry. Sorption of single components confirms the conclusions from previous thermogravimetric studies: $\mathrm{SO}_{2}$ is chemisorbed on cork whereas $\mathrm{H}_{2} \mathrm{O}$ is only physisorbed. Nevertheless, the amounts sorbed are higher for $\mathrm{H}_{2} \mathrm{O}$ than for $\mathrm{SO}_{2}$. Moreover, we have considered in our previous articles that $\mathrm{SO}_{2}$ and $\mathrm{H}_{2} \mathrm{O}$ are adsorbed on cork (Lequin et al. 2009, 2010). In light of the present results, the term adsorption now seems inappropriate. Cork exhibits neither micro- and mesoporosity nor specific surface area, measurable by nitrogen or krypton adsorption and the interaction of $\mathrm{SO}_{2}$ and $\mathrm{H}_{2} \mathrm{O}$ with cork is more like a gas solubility in a polymer rather than a gas adsorption on a solid surface. Thus, the interaction process of the molecules with cork is more likely absorption rather than adsorption, even though the interaction of the first molecules (probably on specific sites located on the external surface of cork) is very similar to an adsorption process. However, without solid experimental proof, we prefer now to label this kind of interaction as sorption.

Concerning the sorption of the binary mixture, the cosorption process is firstly in favor of $\mathrm{SO}_{2}$. As this compound is chemisorbed, it strongly interacts with cork, compared to water. After all chemisorption sites are saturated with $\mathrm{SO}_{2}$, the cosorption process becomes selective to $\mathrm{H}_{2} \mathrm{O}$. This study shows that, even in the presence of water, the partial amount of $\mathrm{SO}_{2}$ sorbed on cork is very low.

In terms of mean sulfur dioxide in a wine bottle, free $\mathrm{SO}_{2}$ may range from 20 to $30 \mathrm{mg}$. $\mathrm{L}^{-1}$, and total $\mathrm{SO}_{2}$ may be $\sim 100$ mg.L. ${ }^{-1}$. The Henry constant for the equilibrium of $\mathrm{SO}_{2}$ between the gas phase and the liquid phase is equal to 0.768 mg. $\mathrm{L}^{-1} \cdot \mathrm{Pa}^{-1}$ at $298 \mathrm{~K}$. Therefore, considering the mean free $\mathrm{SO}_{2}$ concentration, the partial pressure of $\mathrm{SO}_{2}$ in the headspace of a wine bottle is $0.33 \mathrm{hPa}$. Under this pressure, the amount of $\mathrm{SO}_{2}$ sorbed by cork partially hydrated (sorption isotherm given in Lequin et al. 2009) is $\sim 0.1 \mathrm{mg}^{-\mathrm{g}^{-1}}$. In the worst-case scenario, the full cork stopper-not simply the 
surface in contact with wine-will contribute to the sorption of $\mathrm{SO}_{2}$. The mass of $\mathrm{SO}_{2}$ sorbed by a standard cork stopper weighing $\sim 3 \mathrm{~g}$ would be equal to $0.3 \mathrm{mg}$, representing $\sim 1.6 \%$ of the free $\mathrm{SO}_{2}$ in a bottle of wine. Consequently, the decrease in the $\mathrm{SO}_{2}$ content observed by several authors (Keenan et al. 1999, Brajkovich et al. 2005, Godden et al. 2001, 2005, Skouroumounis et al. 2005, Kwiatkowski et al. 2007) during aging of wine stored in bottle cannot be attributed to its sorption on cork. For some of these studies, the sharp decrease in $\mathrm{SO}_{2}$ concentration in wine during the first three months of storage can be attributed to the presence of oxygen in the bottle headspace at bottling (if air has not been withdrawn) and its subsequent dissolution in wine and reaction with $\mathrm{SO}_{2}$. During that time it can also be due to the release of oxygen initially present in the closure (Brajkovich et al. 2005, Lopes et al. 2007). Then the more gradual loss of $\mathrm{SO}_{2}$ observed in subsequent months in those studies can unambiguously be attributed to mass transfer mechanisms of oxygen or $\mathrm{SO}_{2}$ through the closure. According to the chemical potential gradient of these diffusing molecules between the two sides of the closure, oxygen can diffuse from the outside to the inside of the bottle, while $\mathrm{SO}_{2}$ diffusion will occur in the opposite way. Therefore, the study of this kinetic aspect would be of relevant interest.

\section{Literature Cited}

Abdulla, G., A. Belghit, K. Allaf. 2009. Impact of instant controlled pressure drop treatment on moisture adsorption isotherm of cork granules. Dry. Technol. 27:237-247.

Adrados, J.R.G., and R.M.C. Haro. 1994. Variacion de la Humedad de equilibrio del corcho en plancha con la humedad relativa. Modelos de regression no lineal para las isotermas de adsorcion. Invest. Agrar. Sist. Recur. For. 3:199-209.

Brajkovich, M., N. Tibbits, G. Peron, C.M. Lund, S.I. Dykes, P.A. Kilmartin, and L. Nicolau. 2005. Effect of screwcap and cork closures on $\mathrm{SO}_{2}$ levels and aromas in a Sauvignon blanc wine. J. Agric. Food. Chem. 53:10006-10011.

Escudero, A., E. Asensio, J. Cacho, and V. Ferreira. 2002. Sensory and chemical changes of young white wines stored under oxygen. An assessment of the role played by aldehydes and some other important odorants. Food Chem. 77:325-331.

Gibson, L.J., K.E. Easterling, and M.F. Ashby. 1981. The structure and mechanics of cork. Proc. R. Soc. London, Ser. A 377:99-117.

Gil, L., and P. Cortiço. 1998. Cork hygroscopic equilibrium moisture content. Holz Roh. Werkst. 56:355-358.

Godden, P., L. Francis, J. Field, M. Gishen, A. Coulter, P. Valente, P. Hoj, and E. Robinson. 2001. Wine bottle closures: Physical characteristics and effect on composition and sensory properties of a Semillon wine. 1. Performance up to 20 months post-bottling. Aust. J. Grape Wine Res. 7:64-105.

Godden, P., et al. 2005. Towards offering wine to the consumer in optimal condition-The wine, the closures and other packaging variables: A review of AWRI research examining the changes that occur in wine after bottling. Wine Ind. J. 20:20-30.

Karbowiak, T., R.D. Gougeon, J.B. Alinc, L. Brachais, F. Debeaufort, A. Voilley, and D. Chassagne. 2010. Wine oxidation and the role of cork. Crit. Rev. Food Sci. 49:1-33.

Keenan, C.P., M.Y. Gözükara, G.B.Y. Christie, and D.N. Heyes. 1999. Oxygen permeability of macrocrystalline paraffin wax and relevance to wax coatings on natural corks used as wine bottle closures. Aust. J. Grape Wine Res. 5:66-70.

Kwiatkowski, M.J., G.K. Skouroumounis, K.A. Lattey, and E.J. Waters. 2007. The impact of closures, including screw cap with three different headspace volumes, on the composition, colour and sensory properties of a Cabernet Sauvignon wine during two years' storage. Aust. J. Grape Wine Res. 13:81-94.

Lequin, S., D. Chassagne, T. Karbowiak, R.G. Gougeon, L. Brachais, and J.P. Bellat. 2010. Adsorption equilibria of water vapor on cork. J. Agric. Food. Chem. 58:3438-3445.

Lequin, S., T. Karbowiak, L. Brachais, D. Chassagne, and J.P. Bellat. 2009. Adsorption equilibria of sulfur dioxide on cork. Am. J. Enol. Vitic. 60:138-144.

Lopes, P., C. Saucier, P.L. Teisseidre, and Y. Glories. 2007. Main routes of oxygen ingress through different closures into wine bottles. J. Agric. Food Chem. 55:5167-5170.

Moise, J.C., and J.P. Bellat. 2005. Effect of preadsorbed water on the adsorption of $p$-xylene and $m$-xylene mixtures on $\mathrm{BaX}$ and $\mathrm{BaY}$ zeolites. J. Phys. Chem. 109:17239-17244.

Pereira, H. 2007. The chemical composition of cork. In Cork: Biology, Production and Uses, pp. 55-99. Elsevier, Amsterdam.

Ribéreau-Gayon, J. 1963. Phenomena of oxidation and reduction in wines and applications. Am. J. Enol. Vitic. 14:139-143.

Rossi, J.A., Jr., and V.L. Singleton. 1966. Contributions of grape phenols to oxygen absorption and browning of wines. Am. J. Enol. Vitic. 17:231-239.

Silva, S.P., M.A. Sabino, E.M. Fernandes, V.M. Correlo, L.F. Boesel, and R.L. Reis. 2005. Cork: Properties, capabilities and applications. Int. Mater. Rev. 50:345-365.

Sing, K.S.W., D.H. Everett, R.A.W. Haul, L. Moscou, R.A. Pierotti, J. Rouquérol, and T. Siemieniewska. 1985. Reporting physisorption data for gas/solid systems. Pure Appl. Chem. 57:603-619.

Singleton, V.L. 1987. Oxygen with phenols and related reactions in musts, wines, and model systems: Observations and practical implications. Am. J. Enol. Vitic. 38:69-77.

Skouroumounis, G.K., M.J. Kwiatkowski, I.L. Francis, H. Oakey, D.L. Capone, B. Duncan, M.A. Sefton, and E.J. Waters. 2005. The impact of closure type and storage conditions on the composition, colour and flavour properties of a Riesling and a wooded Chardonnay wine during five years' storage. Aust. J. Grape Wine Res. 11:369-377.

Toribio, F., J.P. Bellat, P.H. Nguyen, and M. Dupont. 2004. Adsorption of water vapor by poly(styrenesulfonic acid) sodium salt: Isothermal and isobaric adsorption equilibria. J. Colloid. Interf. Sci. 280:315-321.

Valade, M., I. Tribaut-Sohier, D. Bunner, M. Laurent, D. Moncomble, and D. Tusseau. 2007. Les apports d'oxygène en vinification et leurs impacts sur les vins. Le cas particulier du champagne. $2^{\text {ème }}$ partie. Rev. Fr. Oenol. 222:17-28.

Vidal, J.C., J.C. Boulet, and M. Moutounet. 2004. Les apports d'oxygène au cours des traitements des vins. Bilan des observations sur site. $3^{\text {ème }}$ partie. Rev. Fr. Oenol. 205:25-33.

Waterhouse, A.L., and V.F. Laurie. 2006. Oxidation of wine phenolics: A critical evaluation and hypotheses. Am. J. Enol. Vitic. 57:306-313.

Weber, G., F. Benoit, J.P. Bellat, C. Paulin, P. Mougin, and M. Thomas. 2008. Selective adsorption of ethyl mercaptan on NaX zeolite. Micropor. Mesopor. Mat. 109:184-192.

Wildenradt, H.L., and V.L. Singleton. 1974. The production of aldehydes as a result of oxidation of polyphenolic compounds and its relation to wine aging. Am. J. Enol. Vitic. 25:119-126. 